\title{
Principles for supporting task substitution in Australian general practice
}

\author{
Michael R Kidd, Ian T Watts, Christopher D Mitchell, Lynton G Hudson, Beres C Wenck and Naomi J Cole
}

C omprehensive, integrated primary health care underpins cost-effective national health systems. ${ }^{1,2}$ In Australia, general practice is the foundation of primary care, providing continuing, comprehensive, and coordinated primary health care to the vast majority of Australians.

The fragmentation of care can result in inefficiencies and higher costs, and can pose other risks. ${ }^{2}$ Task substitution in Australian general practice needs to be discussed in the context of supporting the core attributes of general practice, including its continuity, comprehensiveness, and its role in coordination. Otherwise, change might diminish the valuable contribution general practice makes. However, general practice in Australia is in the midst of a workforce crisis, with a shortage of general practitioners $^{3}$ and other professionals integral to general practice, such as nurses. ${ }^{4}$ This crisis provides an impetus and opportunity for innovation in general practice, despite posing a serious challenge for both general practice and the broader health care system.

Defining new roles in general practice may help maintain and enhance the quality of patient care in the face of workforce shortages, but we need to move the discussion beyond task substitution alone. We need to consider:

- whether we need enhancement, substitution, delegation or innovation, ${ }^{5}$

- whether current approaches to task substitution actually achieve this, or whether they result, for example, in supplementing patient care;

- the technical aspects of the skill-mix and its impact at practice-level, as well as the broad issues of organisational change and health policy that will form part of any change strategy; ${ }^{7}$

- the acceptability to GPs of task transfer; and

- GPs' ability to delegate effectively.

Most importantly, we need to assess new approaches to task substitution in terms of benefits and risks to patient care. To do this, we advance the six principles discussed below.

\section{Principles for assessing task substitution}

Roles within general practice teams should support the GP-patient relationship

All roles within the general practice team need to respect and support the GP-patient relationship. Many patients want to be able to identify the GP with whom they have an ongoing and trusted relationship, and many consider their GP as key in linking them with other members of the general practice team. ${ }^{8}$ Patient acceptance of others within the team performing different tasks thus hinges significantly on an effective GP-patient relationship.

In the increasingly complex Australian health system, it is important to support the GP's role as patient advocate. Patient safety and the cost-effectiveness of care require that patients' confidence is maintained and that appropriate investigation and treatment occur. In our health system, GPs provide this vital role.

\section{ABSTRACT}

- The workforce crisis in Australian general practice provides an impetus to consider new roles for other health professionals.

- Any innovations need to be appraised in advance for their potential risks and benefits.

- We propose six principles for this appraisal. These are the need for the new roles to:

$>$ support the relationship between patients and their general practitioners;

> be clearly defined, aligned with competency and with relevant professional registration;

> be supported by practice systems providing safeguards against medical error;

$>$ be underpinned by a system ensuring informed patient consent to activities being undertaken by members of the general practice team;

$>$ be supported by effective medical indemnity insurance and

$>$ be supported with appropriate financing

MJA 2006; 185: 20-22

There is little evidence about the impact of task substitution on Australian GPs. Removing simple tasks may affect the sense of connection between patients and their doctors ("my doctor" or "my patient"), ${ }^{9}$ which is more important when dealing with serious conditions and emotional circumstances. ${ }^{10}$ Thus, we need to carefully appraise any innovations that change the GPpatient relationship, as the impact of compromising this key relationship may be difficult to discern in the short term.

Removing the relatively simple and quick tasks, such as writing medical certificates, immunisations and repeat prescriptions, that currently provide welcome relief in a GP's busy day and the opportunity to "catch up", may lead to increased stress and job dissatisfaction for GPs. While GPs are highly skilled at managing chronic disease, mental health concerns, comorbidity, social issues and the many other complex challenges which present in general practice, removing the relatively simple tasks to allow GPs to focus all their time on the complex tasks of general practice may lead to burnout and further workforce pressures.

We also need to appraise the evidence suggesting that non-GP roles within the general practice team provide optimal benefits where they are supplemental to and supportive of the GP role rather than operating as a substitute for it. ${ }^{11}$

Roles should be defined and aligned with education, training, competency and licensing requirements

The education, training and licensure (registration) of the members of the general practice team need to be aligned. ${ }^{12}$ These key elements have been incorporated into the Australian Council for 
Safety and Quality in Health Care National patient safety education framework. ${ }^{13}$ Compromise on such alignment may risk safety and quality, and may also undermine the legitimacy and acceptance of the roles.

A central challenge is to ensure that the alignment of the roles, training and registration of members of the general practice team remains up to date in the face of changes and advances. Registration that is reliant on attaining minimum required levels of training and competence, and that imposes professional accountability and monitoring, can help.

Australian GPs and general practice nurses have expressed the need and desire for clearly defined roles for nurses in general practice. Further, they have indicated the importance of GPs and practice staff being aware of the scope of the general practice nurse's role, as well as the importance of nurses working within that scope. ${ }^{14}$

Maintaining appropriate knowledge, for example, in the context of constantly changing access to medicines, often lies at the heart of GP concerns about prescribing rights of third parties such as nurses and optometrists. However, preventing otherwise competent staff from undertaking work because the registration framework has not kept pace can also present a problem. For example, the capacity for patients to claim rebates for the work of some Aboriginal health workers is restricted by the requirement that they be registered professionals, but such registration is not available nationally. ${ }^{15}$

\section{Roles need to be supported by practice systems that safeguard against medical error}

Research on whether nurse practitioners working in primary care can provide equivalent care to doctors has not been of sufficient power to detect rare but serious adverse outcomes. ${ }^{16}$ Primary care research suggests that "provider factors", like fatigue and being distracted, are less frequent contributors to error in primary care than "process factors", ${ }^{17}$ like missing results. Thus, we need to complement our focus on individual competence with a systems-based approach to reducing medical error; and we need to move beyond the "person approach" of human fallibility, to a "system approach". ${ }^{18}$ Task substitution needs to be viewed in this context.

We need to continue implementing safeguards like information systems. Clinical and administrative software systems that provide access to records by multiple team members and patient recall facilities are an example of structural safeguards that might help reduce the potential for error in general practice teams. Research suggests improved outcomes from electronic record keeping. ${ }^{19}$ However, we need to appraise the strengths and limitations of the design of these information systems, and the risk of error associated with change itself.

It cannot be assumed that teams will be better or safer, even with highly competent members. Teams may have more "handovers", providing more opportunities for miscommunication. Divergent views on patient management in teams may provide opportunities for different, and sometimes suboptimal, management. Thus, where we want task substitution, it is essential that we actively plan and manage systems that address the errorprone aspects of teamwork, including the transitions themselves.

\section{Roles need to be underpinned by a system that ensures patients' informed consent}

Informed consent is a basic tenet of ethical and safe health care. Patients need to know who is undertaking their care, and have confidence in the competence of the person involved. Australian patients have indicated that they wish their GP to introduce them to the other team members, and serve as a conduit to this care. ${ }^{8}$ As a result, we need to have systems that ensure patients are informed and give consent to the activities being undertaken by the members of the general practice team.

\section{Task transfer needs to be supported by effective medical indemnity insurance}

Where practices seek to include other health care providers in the general practice team, appropriate arrangements need to be in place for medical indemnity cover. In Australia, GPs maintain a central responsibility because of their overall role in patient management and their vicarious liability for their employees. However, medical indemnity insurance arrangements are challenged, for example, in recent suggestions of delegation to midwives, ${ }^{20}$ and it is not clear that the current, doctor-based insurance arrangements can accommodate the delegated model proposed.

Thus, innovative models that bring changes in role and employment status may challenge the effectiveness of our current GP-based medical indemnity cover, and further reform may be required.

\section{Task substitution needs to be supported by appropriate financing to ensure sustainability}

Traditionally, general practice has used the complexity of the care and the face-to-face time with the GP as the basis for billing. Usually there is a mix of activity, some of which has a lower "margin" of financial sustainability. In that context, consideration will need to be given to the impact on practice viability of changes to the mix of services provided by GPs, or to different models for generating fees.

While including other health care providers in the general practice team may provide benefits for patients and improved economic outcomes, it is also likely to require unique approaches to planning, financial support and investment. Non-medically qualified health care professionals, such as general practice nurses, can provide important health interventions that improve health outcomes, thus providing the potential to reduce demand for health services, which in turn flows on to reductions in health care spending. ${ }^{21}$ General practice finances will need to be at a level appropriate to enable general practices to engage appropriately trained and competent health professionals to support high quality and safe care.

It is also necessary to look beyond practice-level financing issues to those at a national level. The structure of the patient subsidies through the Medicare Benefits Schedule (MBS) has a significant impact on general practice, and is determined nationally. Additionally, from the perspective of the national health economy, workforce participation and retention, the length of consultations and other factors like the frequency of requests for tests, will influence the overall financial outcome. ${ }^{6}$ Substituting nurses for doctors in primary care, for example, may not be as cost-effective from this broader perspective. ${ }^{22}$ 


\section{The acceptability of the changes}

While we strongly recommend that the principles we have outlined be considered as a basis for assessing change, change is likely to fail unless it is acceptable to GPs. Thus, acceptability is an important, practical consideration in task substitution.

The idea of a wide range of delegated care was supported at a recent Australian health workforce conference. ${ }^{23}$ However, the willingness of doctors to allow substitution also needs to be considered. True substitution cannot take place if professionals continue to provide the tasks that have been transferred. Efficiency gains are dependent on GPs giving up the activities they delegate and investing their time in activities that only they can perform. ${ }^{24} \mathrm{~A}$ major issue in delegating within general practice teams may be education in both the delegation of activity that is appropriate, and a greater understanding of the process for the management of change. ${ }^{25}$

\section{Conclusion}

There is scope for innovation in the tasks carried out in Australian general practice, but we need a structured way to assess options and ensure that potential risks are minimised, and we need to consider the acceptability of changes.

\section{Competing interests}

None identified.

\section{Author details}

Michael R Kidd, MB BS, MD, FRACGP, President ${ }^{1}$ and Professor and Head, Discipline of General Practice ${ }^{2}$

Ian T Watts, BSW, DipSocPlan, MBA(Exec), National Manager ${ }^{1}$

Christopher D Mitchell, BMed, FRACGP, FACRRM, Chair, National

Rural Faculty ${ }^{1}$

Lynton G Hudson, FRACGP, DipObsRACOG, Chair, National Expert Committee on Standards for General Practices ${ }^{1}$

Beres C Wenck, MB BS, FAMA, Chair, National Standing Committee - GP Advocacy and Support ${ }^{1}$

Naomi J Cole, BNsg, BJS, Program Manager — GP Advocacy and Support ${ }^{1}$

1 The Royal Australian College of General Practitioners, Melbourne, VIC.

2 The University of Sydney, Sydney, NSW.

Correspondence: ian.watts@racgp.org.au

\section{References}

1 Starfield B, Shi L, Macinko J. Contribution of primary care to health systems and health. Milbank Q 2005; 83: 457-502.

2 Starfield B. The challenging face of primary care. Keynote address. Divisions of General Practice Network Forum; 4 Nov 2005; Perth, Australia. Available at: http://www.adgp.com.au/site/content.cfm?page_id=6697\&current_category_code=778 (accessed May 2006).

3 Australian Medical Workforce Advisory Committee. The general practice workforce in Australia: supply and requirements to 2013. AMWAC report 2005.2. Sydney: AMWAC, 2005.

4 Australian Government Productivity Commission. Australia's health workforce. Productivity Commission research report, 22 December 2005. Canberra: Productivity Commission, 2005. Available at: www.pc.gov.au/study/healthworkforce/ finalreport/healthworkforce.pdf (accessed Jun 2006).

5 Joyce CM, McNeil JJ, Stoelwinder JU. More doctors, but not enough: Australian medical workforce supply 2001-2012. Med J Aust 2006; 184: 441-446.

6 Sibbald B, Shen J, McBride A. Changing the skill-mix of the health care workforce. J Health Serv Res Policy 2004; 9 Suppl 1: 28-38.
7 Buchan J, Calman L. Skill-mix and policy change in the health workforce: nurses in advanced roles. OECD Health Working Papers No.17. Paris: Organisation for Economic Co-operation and Development, Feb 2005.

8 Cheek J, Price K, Dawson A, et al. Consumer perceptions of nursing and nurses in general practice. Report. Centre for Research into Nursing and Health Care in collaboration with Consumer Perspectives and Department of General Practice. Adelaide: Adelaide University, Nov 2002. Available at: http://www.health.gov.au/internet/wcms/publishing.nsf/Content/health-pcd-programs-nursing-consrep.htm (accessed Aug 2005)

9 Haggerty JL, Reid RJ, Freeman GK, et al. Continuity of care: a multidisciplinary review. BMJ 2003; 327: 1219-1221.

10 Schers $H$, van de Ven $C$, van den Hoogen $H$, et al. Family medicine trainees still value continuity of care. Fam Med 2004; 36: 51-54.

11 Laurant M, Hermens R, Braspenning J, et al. Impact of nurse practitioners on workload of general practitioners: randomised controlled trial. BMJ 2004; 328: 927. Epub 2004 Apr 6.

12 Mohr JJ, Batalden PB. Improving safety on the front lines: the role of clinical microsystems. Qual Saf Health Care 2002; 11: 45-50.

13 Australian Council for Safety and Quality in Health Care. National patient safety education framework. Canberra: Commonwealth of Australia, 2005

14 Watts I, Foley E, Hutchinson R, et al. General practice nursing in Australia. Melbourne: Royal Australian College of General Practitioners and Royal College of Nursing Australia, 2004. Available at: http:// www.racgp.org.au/downloads/pdf/gpna/gpna_mainreport.pdf (accessed May 2006).

15 Abbott T. New Medicare items for Indigenous health, refugees and palliative care. Media release ABB050/06. 1 May 2006. Available at: http://www.health.gov.au/internet/ministers/publishing.nsf/Content/ B5D62C7982BF5152CA2571610002F01F/\$File/abb050.pdf (accessed May 2006).

16 Horrocks S, Anderson E, Salisbury C. Systematic review of whether nurse practitioners working in primary care can provide equivalent care to doctors. BMJ 2002; 324: 819-823.

17 Rosser W, Dovey S, Bordman R, et al. Medical errors in primary care results of an international study of family practice. Can Fam Physician 2005; 51: 387-392.

18 Reason J. Human error: models and management. BMJ 2000; 320: 768770.

19 Hippisley-Cox J, Pringle M, Cater R, et al. The electronic patient record in primary care - regression or progression? A cross sectional study. BMJ 2003; 326: 1439-1443.

20 Abbott T. New Medicare item for nurses to provide antenatal checks in rural areas. Media release ABB002/06. 9 Jan 2006. Available at: http:// www.health.gov.au/internet/ministers/publishing.nsf/content/ C78F960B4E3BB995CA2570F1000BC1DD/\$File/abb002.pdf (accessed May 2006).

21 Lorig K, Ritter P, Gozalez V. Hispanic chronic disease self-management: a randomized community-based outcome trial. Nurs Res 2003; 52: 361 369.

22 Laurant M, Reeves D, Hermens R, et al. Substitution of doctors by nurses in primary care. Cochrane Database Syst Rev 2005; (2): CD001271.

23 Brooks PM, Ellis N. Health workforce innovation conference. Med J Aust 2006; 184: 105-106.

24 Richardson MSC. Identifying, evaluating and implementing cost-effective skill mix. J Nurs Manage 1999; 5: 265-270.

25 Crossan F, Ferguson D. Exploring nursing skill mix: a review. J Nurs Manage 2005; 13: 356-362.

(Received 8 May 2006, accepted 15 May 2006)

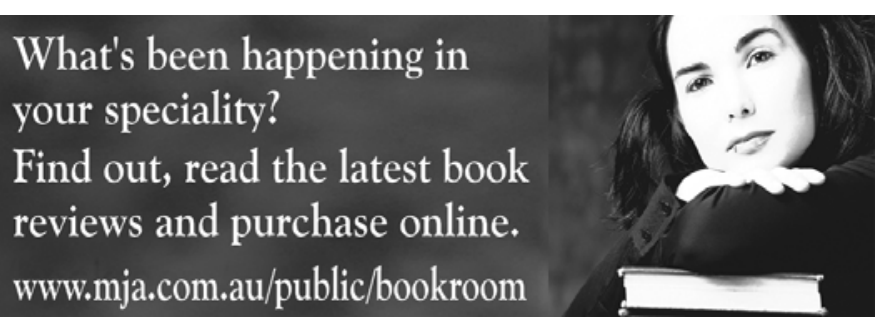

